\title{
Classification of Patients with COPD on LAMA Monotherapy Using the GOLD Criteria: Analysis of a Claims-Linked Patient Survey Study
}

\author{
Riju Ray • Beth Hahn (D) - Richard H. Stanford · John White \\ Breanna Essoi · Alyssa Goolsby Hunter
}

Received: May 16, 2019 / Published online: August 6, 2019

(C) The Author(s) 2019

\begin{abstract}
Introduction: To address the burden of chronic obstructive pulmonary disease (COPD), the Global Initiative for Chronic Obstructive Lung Disease (GOLD) recommends treatment according to classification of patients by symptom severity and exacerbation risk. This post hoc analysis of a previously reported claims-linked, cross-sectional survey [study 205862 (HO-1616642)] classified patients with COPD receiving long-acting muscarinic antagonist (LAMA) monotherapy based on the GOLD 2017 categories. Methods: Eligible patients who were $\geq 40$ years of age, with $\geq 2$ claims with International Classification of Diseases-10th Revision-Clinical Modification COPD diagnosis codes J40-J44 $\geq 30$ days apart during the 12-month baseline period, and $\geq 2$ claims for LAMA monotherapy
\end{abstract}

Enhanced Digital Features To view enhanced digital features for this article go to https://doi.org/10.6084/ m9.figshare.8982272.

R. Ray

US Medical Affairs, GSK, Research Triangle Park, NC, USA

B. Hahn $(\bowtie) \cdot$ R. H. Stanford

US Value Evidence and Outcomes, GSK, Research

Triangle Park, NC, USA

e-mail: beth.a.hahn@gsk.com

J. White - B. Essoi · A. G. Hunter

Health Economics and Outcomes Research, Optum, Eden Prairie, MN, USA in the 6 months prior to identification, were identified using claims data from the Optum Research Database. Patients completed a survey assessing modified Medical Research Council (mMRC) Dyspnea Scale and COPD Assessment Test (CAT) scores and demographics; clinical characteristics were assessed from claims and survey data, while exacerbation history was assessed from claims data. GOLD symptom severity classifications were low (groups A and C) for patients with low scores on both the CAT and mMRC scales (scores of $<10$ and $0-1$, respectively), and high (groups $\mathrm{B}$ and $\mathrm{D}$ ) for patients with high scores on either scale (scores of $\geq 10$ and $2-4$, respectively).

Results: Of 433 patients included, $85.5 \%$ reported a CAT total score $\geq 10$, and $45.5 \%$ reported mMRC grades $2-4$. During the baseline period, $63.7 \%$ of patients had $\leq 1$ moderate and 0 severe (hospitalized) exacerbations, and $36.3 \%$ had $\geq 1$ severe or $\geq 2$ moderate exacerbation(s). The proportions of patients with each GOLD classification were: A: 9.0\%; B: 54.7\%; C: 4.6\%; D: 31.6\%.

Conclusions: In this population, over $85 \%$ of LAMA monotherapy users have symptoms and/ or exacerbation risk that may necessitate therapy escalation according to 2017 GOLD guidelines.

Funding: GlaxoSmithKline [study 205862 (HO16-16642)]. 
Keywords: Bronchodilator agents; COPD; Exacerbation; GOLD; LAMA monotherapy; Patient-reported outcome measures

\section{INTRODUCTION}

Chronic obstructive pulmonary disease (COPD) is a leading global cause of morbidity and mortality [1, 2]. In 2015, 3.2 million deaths worldwide were attributed to the disease, and chronic lower respiratory disease, including COPD, was the third leading cause of death in the United States (USA) [1, 2]. The high clinical and economic burden of COPD is well documented [3-5]; key factors contributing to this burden include disease severity and the presence of frequent exacerbations, which incur considerable costs to patients and health care systems [3-6]. The key goals of pharmacological therapy for COPD, therefore, are to reduce symptoms and the frequency and severity of exacerbations [7].

Since 2017, the Global Initiative for Chronic Obstructive Lung Disease (GOLD) report has included treatment recommendations that are stratified by patient classifications based on assessment of symptom severity and exacerbation risk $[7,8]$. Patients are categorized into GOLD groups A, B, C, or D using scores from patient-reported outcome (PRO) measures [the modified Medical Research Council (mMRC) Dyspnea Scale or the COPD Assessment Test (CAT)], and moderate/severe exacerbation history, as follows: GOLD A, low symptom severity and low exacerbation risk; GOLD B, high symptom severity and low exacerbation risk; GOLD C, low symptom severity and high exacerbation risk; and GOLD D, high symptom severity and high exacerbation risk $[7,8]$.

Low symptom severity is defined as mMRC grades $0-1$ or a CAT total score $<10$, and high symptom severity is defined as mMRC grades $2-4$ or CAT total score $\geq 10$. Low exacerbation risk is defined as a history of 0 or 1 exacerbation (not leading to hospitalization); high exacerbation risk is defined as a history of $\geq 2$ exacerbations (not leading to hospitalization) or $\geq 1$ exacerbation (leading to hospitalization) [7, 8].
To fully understand symptom severity in COPD, a comprehensive assessment of symptoms is recommended $[7,8]$. There has been increasing recognition of the value of $\mathrm{mMRC}$ and CAT scores as important indicators of symptom severity in COPD [9], as reflected by their recommended use in the GOLD report $[7,8]$. The mMRC quantifies the disability associated with breathlessness by identifying whether breathlessness occurs when it should not (grades 0-1) and by evaluating exercise limitation (grades 2-4) [9]; it has been demonstrated to correlate well with other measures of health status $[10,11]$. The CAT is an eight-item validated questionnaire that measures the most salient symptoms of COPD, including cough, chest tightness, breathlessness, and activity limitation attributed to COPD symptoms [12]. The total score ranges from 0 to 40 , with higher scores $(\geq 10)$ indicating a higher level of symptom severity than lower scores (0-9). The CAT has been demonstrated to be a simple and reliable measure of overall COPD-related health status, and correlates with other measures of disease severity [13-15].

It is recommended that patients in GOLD group A receive short- or long-acting bronchodilator monotherapy to control symptoms $[7,8]$. For patients in GOLD groups $B$ and $C$ who experience persistent symptoms or further exacerbations, escalation to long-acting muscarinic antagonist plus long-acting $\beta_{2}$-agonist (LAMA + LABA) combination therapy is recommended [escalation to a LABA + inhaled corticosteroid (ICS) combination is a secondary option for patients in group C]. Patients in group $\mathrm{D}$ are recommended to escalate to triple therapy (LAMA + LABA + ICS) if further exacerbations occur $[7,8]$.

A recent claims-linked cross-sectional study of patients with COPD treated with LAMA monotherapy found that a significant proportion of these patients remained symptomatic based on patient-reported burden of illness measures [16], and recommended that physicians should consider the use of PROs, such as the CAT, as part of routine care for patients with COPD [17]. This post hoc exploratory analysis of this study [study 205862 (HO-16-16642)] [16] classified patients with COPD receiving LAMA 
monotherapy according to the categories of exacerbation risk and patient-reported symptom severity described in the GOLD 2017 report [8].

\section{METHODS}

\section{Study Design and Population}

This was a post hoc analysis of data from a previously reported claims-linked, cross-sectional survey of patients with prevalent COPD prescribed LAMA monotherapy [study 205862 (HO-16-16642)] [16]. Patients throughout the USA were identified using enrollment, medical, and pharmacy records from the proprietary Optum Research Database (ORD), a large database containing medical and pharmacy data from individuals enrolled in commercial and Medicare Advantage (MA) health plans with a large US health insurer, from October 1, 2015, to September 30, 2016.

Inclusion and exclusion criteria were previously reported [16]; briefly, eligible patients were $\geq 40$ years of age with $\geq 2$ medical claims for COPD [International Classification of Disease 10th Revision Clinical Modification (ICD10-CM) codes J40-J44] at least 30 days apart during the 12-month baseline period and $\geq 2$ claims for LAMA monotherapy during the 6-month period prior to identification. Patients were excluded if, during the 12-month baseline period, they had evidence of lung cancer, or had prescription claims for any ICS-or LABA-containing therapy but did not self-report a current LAMA prescription.

Eligible patients identified from the claims were subsequently recruited by mail and consented to participation in the study by return of a completed paper survey and/or 7-day daily symptom diary. Data from the survey and the diary were collected using a modified Dillman method over a 9-week period from October to December 2016 [18]. Patients were paid \$25 following return of the survey and/or the diary, up to a maximum of $\$ 50$ per patient.

Prior to data collection, the study was approved by the New England Institutional Review Board (NEIRB \# 120160900; September 9, 2016). The study was conducted in accordance with the ethical standards of the institutional and/or national research committee and with the 1964 Declaration of Helsinki and its later amendments or comparable ethical standards.

\section{Outcome Measures}

Data on (socio)demographic and clinical characteristics were captured from both the patient-reported survey and patient medical and pharmacy claims. In this post hoc analysis, patients were categorized into mutually exclusive groups based on the GOLD 2017 classifications (GOLD group A, B, C, or D) using patient-reported mMRC and CAT scores, as well as exacerbation histories obtained from medical and pharmacy claims data (data from the daily diary were not employed in this analysis). To be classified as having low symptom severity (GOLD groups A and C), patients were required to have low symptom severity as measured by both CAT score and mMRC grade; however, patients with either high CAT score or high mMRC grade were included in the high symptom severity categories (GOLD groups B and D).

Severe exacerbations were defined as qualifying COPD hospitalization events; moderate exacerbations were defined as a COPD emergency department event, or a COPD-related ambulatory event, with a prescription for an antibiotic or oral corticosteroid received within 5 days of the encounter. Spirometry results were not assessed as data were not available.

\section{Statistical Analyses}

The analysis population comprised patients with complete, evaluable matched claims, survey, and diary data who met all study inclusion and exclusion criteria [16]. Statistical analyses were performed using SAS software (SAS Institute Inc., Cary, NC, USA, version 9.4) on a Unix platform. All study variables were analyzed descriptively; statistical significance was defined as $p<0.05$. For claims data and survey data, $n$ (\%) was calculated for dichotomous and polychotomous variables, and mean, median, and standard deviation (SD) values, ranges, and 
percentiles were calculated for continuous variables.

\section{RESULTS}

\section{Patients}

A total of 2275 patients fulfilled the eligibility criteria and were mailed surveys to participate in the study, with 528 patients completing the survey [16]. The response rate was $29.8 \%$ based on the American Association for Public Opinion Research Response Rate \#4 (AAPOR RR4) calculation [19]. The final evaluable population included 433 patients with self-reported receipt of LAMA monotherapy with matched claims, survey, and diary data. Demographic and clinical characteristics have been presented previously [16]. Briefly, 326/431 patients (75.6\%) of the population were $\geq 65$ years of age [mean (SD) age 71.0 (9.4) years] and 259/433 (59.8\%) were female. The prevalence of comorbidities was relatively high, with a baseline mean (SD) Quan-Charlson score of 2.2 (1.6), with hypertension being the most commonly reported COPD-related comorbidity (330/433 patients; $76.2 \%)$.

\section{Symptom Severity}

The majority of patients reported high levels of symptom severity: the mean (SD) CAT total score was 18.5 (8.4), with 370/433 patients $(85.5 \%)$ reporting a CAT total score $\geq 10$, while the mean (SD) mMRC score was 1.6 (1.0), with $197 / 433$ patients $(45.5 \%)$ reporting mMRC grades 2-4 (reflecting high levels of dyspnea) [16]. Almost half of patients (193/433; 44.6\%) had high levels of symptom severity with both a CAT score $\geq 10$ and a mMRC score $\geq 2$, while only $59 / 433$ patients (13.6\%) reported low levels of symptom severity as measured by both the CAT and mMRC (Table 1).

\section{Exacerbations}

During the 12-month baseline period, 236/433 patients $(54.5 \%)$ experienced $\geq 1$ moderate or
Table 1 Symptom severity scores as assessed by CAT, mMRC, or both $(N=433)$

\begin{tabular}{lc}
\hline Patient-reported outcomes & $\boldsymbol{n}(\%)$ \\
\hline mMRC categories $^{\mathrm{a}}$ & $236(54.5)$ \\
Grades 0-1 & $197(45.5)$ \\
Grades 2-4 & \\
CAT impact categories ${ }^{\mathrm{b}}$ & $63(14.5)$ \\
Low impact (CAT 0-9) & $370(85.5)$ \\
High impact (CAT 10-40) & \\
CAT impact and mMRC categories & $59(13.6)$ \\
CAT score 0-9 and mMRC grades 0-1 & $4(40.9)$ \\
CAT score 10-40 and mMRC grades 0-1 & $177(40.9)$ \\
CAT score 0-9 and mMRC grades 2-4 & $4(0.9)$ \\
CAT score 10-40 and mMRC grades 2-4 & $193(44.6)$ \\
\hline
\end{tabular}

Percentages may not sum to 100 due to rounding CAT COPD Assessment Test, COPD chronic obstructive pulmonary disease, $m M R C$ modified Medical Research Council Dyspnea Score

${ }^{a}$ Higher mMRC values indicate greater dyspnea

${ }^{b}$ Higher CAT values indicate greater severity

severe exacerbation; $191 / 433$ patients (44.1\%) had $\geq 1$ moderate exacerbation, while 93/433 patients $(21.5 \%)$ had $\geq 1$ severe exacerbation. When classified into the mutually exclusive exacerbation categories presented in the GOLD group classifications [8], 276/433 patients (63.7\%) had either 0 or 1 moderate exacerbation (with no severe exacerbations), and 157/433 patients (36.3\%) had $\geq 1$ severe or $\geq 2$ moderate exacerbation(s). Among those in the latter category, a greater proportion of patients had $\geq 1$ severe exacerbation than $\geq 2$ moderate exacerbations (Table 2).

\section{Stratification Using GOLD 2017 Classifications}

Patients were stratified according to symptom severity using the GOLD 2017 classifications [8], which define low symptom severity as low scores on both the CAT and mMRC measures, 
Table 2 Claims-based exacerbations during 12-month baseline period $(N=433)$

\begin{tabular}{l}
\hline $\begin{array}{l}\text { Exacerbations during the 12-month } \\
\text { baseline period }^{\mathrm{a}}\end{array}$ \\
\hline
\end{tabular}

Exacerbation incidence ${ }^{b}$

$\geq 1$ Exacerbation (moderate/severe) $236(54.5)$

No exacerbations $197(45.5)$

Exacerbation categories-3 groups ${ }^{\mathrm{b}}$

$\geq 1$ Severe exacerbation

$\geq 2$ Moderate exacerbations (and 0 severe)

$64(14.8)$

0 or 1 Moderate exacerbation (and 0 severe) 276 (63.7)

Exacerbation categories-2 groups ${ }^{\mathrm{b}}$

$\geq 2$ Moderate or $\geq 1$ severe exacerbation(s) 157 (36.3)

0 or 1 Moderate exacerbation (and 0 severe) 276 (63.7)

$C O P D$ chronic obstructive pulmonary disease

${ }^{\text {a }}$ Severe exacerbations were defined as qualifying COPD hospitalization events, and moderate exacerbations were defined as a COPD emergency department event or a COPD ambulatory event, with a prescription for an antibiotic or oral corticosteroid received within 5 days of the encounter

${ }^{\mathrm{b}}$ Categories are mutually exclusive

and high symptom severity as a high score on either the CAT or the mMRC measure. Following stratification, $39 / 433$ patients $(9.0 \%)$ had symptoms and exacerbation risk consistent with GOLD group A; $237 / 433$ patients (54.7\%) were consistent with GOLD group B; 20/433 patients (4.6\%) were consistent with GOLD group C; and $137 / 433$ patients (31.6\%) were consistent with GOLD group D (Fig. 1).

\section{DISCUSSION}

This post hoc analysis of a claims-linked survey study assessing symptom burden, exacerbation history, and GOLD classification revealed that patients with COPD remained symptomatic based on combined PRO and health service utilization measures, despite being treated with LAMA monotherapy. Based on current treatment recommendations $[7,8]$, we would have anticipated that a higher proportion of patients would have been classified as having both low exacerbation risk and low symptom severity (GOLD group A), and would therefore have been well managed with LAMA monotherapy. However, over three times (31.6\%) as many study participants were classified as having both high exacerbation risk and high symptom severity (GOLD D) as those classified as having both low exacerbation risk and low symptom severity, with fewer than 1 in 10 patients $(9.0 \%)$ meeting the criteria for GOLD group A. Additionally, the proportion of patients classified as GOLD group C (low symptom severity and high exacerbation risk) was very low (4.6\%).

This combined evidence from the PROs and claims data suggests that the majority of patients had exacerbations, or symptoms that were not well controlled, on LAMA monotherapy, and that some of these patients may benefit from therapy escalation. Based on the recommendations outlined in the GOLD report $[7,8]$, over $85 \%$ of the patients in this study were identified as potential candidates for additional therapy. For patients with persistent symptoms on monotherapy, escalation to dual LAMA + LABA therapy is recommended [7] based on the improvements in lung function and patient-reported symptoms demonstrated versus the component monotherapies in multiple clinical trials [20-24]. There is also evidence to suggest that there is a small but nonsignificant reduction in exacerbation rates with dual LAMA + LABA therapy versus LAMA monotherapy [25]. Escalation to ICS + LABA therapy is an alternative recommendation for patients with a high exacerbation risk [7, 8]. However, limited data are available from direct comparisons of efficacy between LAMA and ICS + LABA therapies [26-29]; and while results from two studies suggest a potential reduction in exacerbations with ICS + LABA therapy $[28,29]$, results from another study found no difference in rates between the treatment arms [27]. Patients who develop further exacerbations or experience persistent symptoms on LABA + LAMA or ICS + LABA therapy are recommended to escalate to triple therapy 


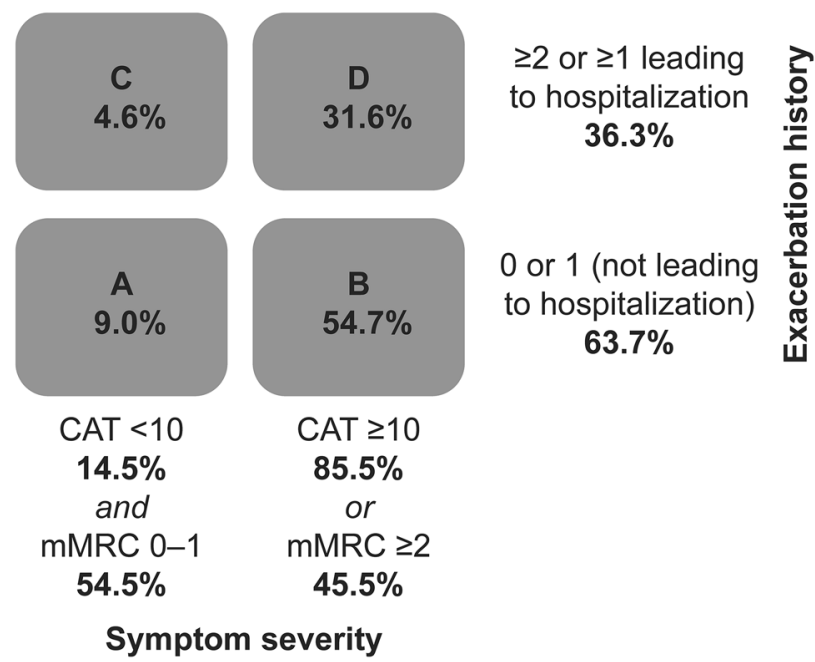

Fig. 1 Classification of patients according to the GOLD 2017 groups [8]. Percentages may not sum to 100 due to rounding. CAT COPD Assessment Test, COPD chronic

(LAMA + LABA + ICS) following evidence of benefits in lung function, exacerbation incidence, and PROs in multiple studies [30-36].

The considerable gap between real-world practice and guideline-recommended care observed in this study is consistent with observations from several previous studies that have reported poor compliance with guideline recommendations [37-42]. Considerable undertreatment in COPD has been observed: studies in the USA [39-41] and the United Kingdom [43] have reported high proportions of patients (43-68\%) not receiving any maintenance medications, with one study noting that $36 \%$ of previously diagnosed patients with at least one prior exacerbation were not prescribed long-acting maintenance medications [39]. An epidemiological study in Spain also observed that $17 \%$ of frequent exacerbators and $13.6 \%$ of patients classified as GOLD grade 4 (forced expiratory volume in $1 \mathrm{~s}<30 \%$ predicted) remained untreated [38]. Additionally, relatively high use of ICS-containing regimens compared with other maintenance regimens has been observed in several studies $[38,40-43]$, even in patients without a history of exacerbations $[38,42]$ or with lower GOLD grades $[41,42]$, contrary to guideline recommendations. Further research is required to investigate the reasons for the lack of obstructive pulmonary disease, GOLD Global Initiative for Chronic Obstructive Lung Disease, $m M R C$ modified Medical Research Council Dyspnea Scale

conformity to guideline recommendations and to address this important issue.

Another observation of this study was that the classification of patients differed depending on the measure used to assess symptom severity: $54.5 \%$ of patients were classified as having low symptom severity using the mMRC scale, whereas only $14.5 \%$ of patients were in this category when classified using the CAT. The potential for inconsistent GOLD classification can impact treatment; it has been suggested that reliance on one marker of symptom severity may result in undertreatment for many patients [44]. Undertreatment has been shown to result in worse short- and long-term outcomes in terms of symptoms and health care resource utilization [45]. However, despite the risk of undertreatment when patients are classified using only one measure of symptom severity, the GOLD report states that patients can be classified as having high symptom severity using only one of the mMRC or CAT [7]. Further research is needed into the various approaches that have been proposed to address the discrepancies in GOLD classifications, including changing the mMRC or CAT cutpoints used or performing both assessments and using the higher result [11, 44, 46, 47].

Limitations of this study include those typically associated with claims-linked studies. 
These include the inability of the presence of a claim for a filled prescription to demonstrate definitively that the medication was consumed or taken as prescribed, a lack of capture of any medications filled over the counter or provided as samples by a physician, and the inability of the presence of a diagnosis code on a medical claim to provide conclusive evidence of the associated disease. Clinical observations such as spirometry and thoracic imaging were also unavailable. While a claims-based diagnosis code is not positive evidence of the presence of the disease, the study design aimed to mitigate these limitations by requiring multiple medical and pharmacy claims with COPD diagnosis and treatment codes for eligibility. To corroborate these claims-based codes, patients were asked in the survey whether they had received a diagnosis of COPD from a health care provider, and to describe their current COPD medication. In addition, many patients in this prevalent population had multiple comorbidities, particularly hypertension, and it is therefore possible that dyspnea reported by these patients may not have been due exclusively to COPD. However, a high frequency of comorbidities is an expected characteristic of a real-world population of patients with COPD, which shares several risk factors with other chronic diseases. Since this study did not include measures of adherence, it is not possible to determine whether inadequate symptom control was due to medication-related behaviors among the study population, such as poor adherence or incorrect inhaler administration. A further potential limitation is that the enrollment of study participants insured with commercial or MA health plans may limit the generalizability of results to other populations such as uninsured patients or those outside the USA.

\section{CONCLUSIONS}

The results of this study demonstrate that a large proportion of patients with prevalent COPD treated with LAMA monotherapy had symptoms that were not well controlled: over $85 \%$ of patients reported a high symptom burden, with less than $5 \%$ of patients reporting low symptoms and high exacerbation risks. The majority of patients were categorized as either GOLD B or D, and may therefore benefit from escalation of therapy, as outlined in the GOLD report [7], and/or exacerbation risk reduction strategies.

\section{ACKNOWLEDGEMENTS}

The authors thank the participants of this study.

Funding. This study was funded by GlaxoSmithKline [GSK Study Number 205862 (HO-16-16642)]. The funders of the study had a role in the study design, data analysis, data interpretation, and writing of the report. The article processing charges associated with this publication were funded by GSK. The study was conducted by Optum and funded by GSK. Employees of Optum were not paid for manuscript development. All authors had full access to the data in this study and take complete responsibility for the integrity of the data and accuracy of the data analysis.

Medical Writing, Editorial, and Other Assistance. Editorial support (in the form of writing assistance, assembling tables and figures, collating author comments, grammatical editing and referencing) was provided by Hayley Mukherjee, PhD, at Fishawack Indicia Ltd, UK, and was funded by GSK.

Authorship. All named authors meet the International Committee of Medical Journal Editors (ICMJE) criteria for authorship for this article, take responsibility for the integrity of the work, contributed to the writing and reviewing of the manuscript, and have given final approval for the version to be published. The corresponding author had the final responsibility to submit for publication and is the guarantor.

Authorship Contributions. BH was involved in the conception/design of the study and analysis/interpretation of data. RHS was involved in the conception/design of the study 
and analysis/interpretation of data. AGH was involved in the conception/design of the study, acquisition of data and analysis/interpretation of data. JW was involved in the acquisition of data and analysis/interpretation of data. BE was involved in the acquisition of data. RR was involved in the conception/design of the study and analysis/interpretation of data.

Disclosures. Riju Ray is an employee of GSK and hold stocks/shares in GSK. Beth Hahn is an employee of GSK and hold stocks/shares in GSK. Richard H Stanford is an employee of GSK and hold stocks/shares in GSK. John White is an employee of Optum, which was contracted by GSK to conduct the study. Breanna Essoi is an employee of Optum, which was contracted by GSK to conduct the study. Alyssa Goolsby Hunter is an employee of Optum, which was contracted by GSK to conduct the study. Alyssa Goolsby Hunter holds stocks/shares in Optum's parent company, UnitedHealth Group (UNH). Employees of Optum were not paid for manuscript development.

Compliance with Ethics Guidelines. Prior to data collection, the study was approved by the New England Institutional Review Board (NEIRB \#120160900; September 9, 2016). The study was conducted in accordance with the ethical standards of the institutional and/or national research committee and with the 1964 Helsinki Declaration and its later amendments or comparable ethical standards.

Data Availability Statement. This study was a collaboration between GSK and Optum. GSK makes available anonymized individual participant data and associated documents from interventional clinical studies which evaluate medicines, upon approval of proposals submitted to www.clinicalstudydatarequest.com. To access data for other types of GSK sponsored research, for study documents without patientlevel data and for clinical studies not listed, please submit an inquiry via the website. The datasets analyzed during the current study are not publicly available. For this manuscript, the data are contained in a database owned by Optum and contain proprietary elements and, therefore, cannot be broadly disclosed or made publicly available at this time. The disclosure of these data to third-party clients assumes that certain data security and privacy protocols are in place and that the third-party client has executed Optum's standard license agreement, which includes restrictive covenants governing the use of the data.

Open Access. This article is distributed under the terms of the Creative Commons Attribution-NonCommercial 4.0 International License (http://creativecommons.org/licenses/ by-nc/4.0/), which permits any noncommercial use, distribution, and reproduction in any medium, provided you give appropriate credit to the original author(s) and the source, provide a link to the Creative Commons license, and indicate if changes were made.

\section{REFERENCES}

1. Soriano JB, Abajobir AA, Abate KH, Abera SF, Agrawal A, Ahmed MB, Aichour AN, Aichour I, Aichour MT, Alam K, Alam N. Global, regional, and national deaths, prevalence, disability-adjusted life years, and years lived with disability for chronic obstructive pulmonary disease and asthma, 1990-2015: a systematic analysis for the global burden of disease study 2015. Lancet Respir Med. 2017;5(9):691-706.

2. US Centers for Disease Control and Prevention. Health, United States, 2016. 2016. https://www.cdc. gov/nchs/data/hus/hus16.pdf\#019. Accessed June 12, 2018.

3. Ehteshami-Afshar S, FitzGerald JM, Doyle-Waters MM, Sadatsafavi M. The global economic burden of asthma and chronic obstructive pulmonary disease. Int J Tuberc Lung Dis. 2016;20(1):11-23.

4. Lopez-Campos JL, Tan W, Soriano JB. Global burden of COPD. Respirology. 2016;21(1):14-23.

5. Guarascio AJ, Ray SM, Finch CK, Self TH. The clinical and economic burden of chronic obstructive pulmonary disease in the USA. ClinicoEcon Outcomes Res CEOR. 2013;5:235-45.

6. Toy EL, Gallagher KF, Stanley EL, Swensen AR, Duh MS. The economic impact of exacerbations of chronic obstructive pulmonary disease and exacerbation definition: a review. COPD. 2010;7(3): 214-28. 
7. Global Initiative for Chronic Obstructive Lung Disease. Global Strategy for the Diagnosis, Management and Prevention of Chronic Obstructive Pulmonary Disease. 2018. http://goldcopd.org/ gold-reports/. Accessed Sept, 282017.

8. Global Initiative for Chronic Obstructive Lung Disease. Global Strategy for the Diagnosis, Management and Prevention of Chronic Obstructive Pulmonary Disease. 2017. http://goldcopd.org/ gold-2017-global-strategy-diagnosis-managementprevention-copd/. Accessed May, 82018.

9. Cazzola M, Hanania NA, MacNee W, Rudell K, Hackford C, Tamimi N. A review of the most common patient-reported outcomes in COPD-revisiting current knowledge and estimating future challenges. Int $\mathrm{J}$ Chronic Obstr Pulm Dis. 2015;10:725-38.

10. Bestall JC, Paul EA, Garrod R, Garnham R, Jones PW, Wedzicha JA. Usefulness of the Medical Research Council (MRC) dyspnoea scale as a measure of disability in patients with chronic obstructive pulmonary disease. Thorax. 1999;54(7):581-6.

11. Jones PW, Adamek L, Nadeau G, Banik N. Comparisons of health status scores with MRC grades in COPD: implications for the GOLD 2011 classification. Eur Respir J. 2013;42(3):647-54.

12. Karloh M, Fleig Mayer A, Maurici R, Pizzichini MMM, Jones PW, Pizzichini E. The COPD assessment test: what do we know so far? A systematic review and meta-analysis about clinical outcomes prediction and classification of patients into gold stages. Chest. 2016;149(2):413-25.

13. Jones PW, Brusselle G, Dal Negro RW, et al. Properties of the COPD assessment test in a cross-sectional European study. Eur Respir J. 2011;38(1):29-35.

14. Lee SD, Huang MS, Kang J, et al. The COPD assessment test (CAT) assists prediction of COPD exacerbations in high-risk patients. Respir Med. 2014;108(4):600-8.

15. Jones PW, Harding G, Berry P, Wiklund I, Chen WH, Kline Leidy N. Development and first validation of the COPD assessment test. Eur Resp J. 2009;34(3):648-54.

16. Hahn B, Stanford RH, Goolsby Hunter A, Essoi B, White J, Ray R. Patient-reported burden of illness in a prevalent COPD population treated with longacting muscarinic antagonist (LAMA) monotherapy: a claims-linked patient survey study. Pulm Ther. 2019;5(1):69-80.

17. Hahn B, Stanford RH, Goolsby Hunter A, Essoi B, White J, Ray R. Burden of symptoms among patients with COPD on LAMA monotherapy. Am J Respir Crit Care Med. 2018;197:A4995.

18. Dillman D, Smyth J, Christian L. Internet, mail, and mixed-mode surveys: the tailored design method. 4th ed. New Jersey: Wiley; 2014.

19. The American Association for Public Opinion Research. Standard Definitions: Final Dispositions of Case Codes and Outcome Rates for Surveys. 2015. https://www.aapor.org/AAPOR_Main/media/ MainSiteFiles/Standard-Definitions2015_8thEd.pdf. Accessed May, 82018.

20. Bateman ED, Ferguson GT, Barnes N, et al. Dual bronchodilation with QVA149 versus single bronchodilator therapy: the SHINE study. Eur Respir J. 2013;42(6):1484-94.

21. Maleki-Yazdi MR, Kaelin T, Richard N, Zvarich M, Church A. Efficacy and safety of umeclidinium/vilanterol 62.5/25 $\mathrm{mcg}$ and tiotropium $18 \mathrm{mcg}$ in chronic obstructive pulmonary disease: results of a 24-week, randomized, controlled trial. Respir Med. 2014;108(12):1752-60.

22. Tashkin DP, Pearle J, Iezzoni D, Varghese ST. Formoterol and tiotropium compared with tiotropium alone for treatment of COPD. COPD. 2009;6(1): $17-25$.

23. van Noord JA, Aumann JL, Janssens E, et al. Combining tiotropium and salmeterol in COPD: effects on airflow obstruction and symptoms. Respir Med. 2010;104(7):995-1004.

24. Wedzicha JA, Decramer M, Ficker JH, et al. Analysis of chronic obstructive pulmonary disease exacerbations with the dual bronchodilator QVA149 compared with glycopyrronium and tiotropium (SPARK): a randomised, double-blind, parallelgroup study. Lancet Respir Med. 2013;1(3): 199-209.

25. Calverley PMA, Anzueto AR, Carter K, et al. Tiotropium and olodaterol in the prevention of chronic obstructive pulmonary disease exacerbations (DYNAGITO): a double-blind, randomised, parallel-group, active-controlled trial. Lancet Respir Med. 2018;6(5):337-44.

26. Welsh EJ, Cates CJ, Poole P. Combination inhaled steroid and long-acting beta2-agonist versus tiotropium for chronic obstructive pulmonary disease. Cochrane Database Syst Rev. 2013;5:CD007891.

27. Wedzicha JA, Calverley PM, Seemungal TA, et al. The prevention of chronic obstructive pulmonary disease exacerbations by salmeterol/fluticasone propionate or tiotropium bromide. Am J Respir Crit Care Med. 2008;177(1):19-26. 
28. Trudo F, Kern DM, Davis JR, et al. Comparative effectiveness of budesonide/formoterol combination and tiotropium bromide among COPD patients new to these controller treatments. Int J Chronic Obstr Pulm Dis. 2015;10:2055-66.

29. Covelli H, Pek B, Schenkenberger I, Scott-Wilson C, Emmett A, Crim C. Efficacy and safety of fluticasone furoate/vilanterol or tiotropium in subjects with COPD at cardiovascular risk. Int J Chronic Obstr Pulm Dis. 2016;11:1-12.

30. Short PM, Williamson PA, Elder DHJ, Lipworth SIW, Schembri S, Lipworth BJ. The impact of tiotropium on mortality and exacerbations when added to inhaled corticosteroids and long-acting beta-agonist therapy in COPD. Chest. 2012;141(1):81-6.

31. Welte T, Miravitlles M, Hernandez P, et al. Efficacy and tolerability of budesonide/formoterol added to tiotropium in patients with chronic obstructive pulmonary disease. Am J Respir Crit Care Med. 2009;180(8):741-50.

32. Lipson DA, Barnacle H, Birk R, et al. FULFIL trial: once-daily triple therapy for patients with chronic obstructive pulmonary disease. Am J Respir Crit Care Med. 2017;196(4):438-46.

33. Singh D, Papi A, Corradi $M$, et al. Single inhaler triple therapy versus inhaled corticosteroid plus long-acting beta2-agonist therapy for chronic obstructive pulmonary disease (TRILOGY): a double-blind, parallel group, randomised controlled trial. Lancet. 2016;388(10048):963-73.

34. Vestbo J, Papi A, Corradi M, et al. Single inhaler extrafine triple therapy versus long-acting muscarinic antagonist therapy for chronic obstructive pulmonary disease (TRINITY): a double-blind, parallel group, randomised controlled trial. Lancet. 2017;389(10082):1919-29.

35. Lipson DA, Barnhart F, Brealey N, et al. Once-daily single-inhaler triple versus dual therapy in patients with COPD. N Engl J Med. 2018;378(18):1671-80.

36. Papi A, Vestbo J, Fabbri L, et al. Extrafine inhaled triple therapy versus dual bronchodilator therapy in chronic obstructive pulmonary disease (TRIBUTE): a double-blind, parallel group, randomised controlled trial. Lancet. 2018;391(10125):1076-84.

37. Asche CV, Leader S, Plauschinat C, et al. Adherence to current guidelines for chronic obstructive pulmonary disease (COPD) among patients treated with combination of long-acting bronchodilators or inhaled corticosteroids. Int J Chronic Obstr Pulm Dis. 2012;7:201-9.

38. Barrecheguren M, Monteagudo M, Ferrer J, et al. Treatment patterns in COPD patients newly diagnosed in primary care. A population-based study. Respir Med. 2016;111:47-53.

39. Diette GB, Dalal AA, D'Souza AO, Lunacsek OE, Nagar SP. Treatment patterns of chronic obstructive pulmonary disease in employed adults in the United States. Int J Chronic Obstr Pulm Dis. 2015;10:415-22.

40. Petite SE. Characterization of chronic obstructive pulmonary disease prescribing patterns in the United States. Pulm Pharmacol Ther. 2018;49:119-22.

41. Wallace A, Zubek V, Kaila S, et al. Real-world treatment patterns among newly diagnosed COPD patients according to GOLD airflow limitation severity classification in a US commercially insured/medicare advantage population. Chest. 2017;152(4):A774.

42. Price D, West D, Brusselle G, et al. Management of COPD in the UK primary-care setting: an analysis of real-life prescribing patterns. Int J Chronic Obstr Pulm Dis. 2014;9:889-904.

43. Wurst KE, Punekar YS, Shukla A. Treatment evolution after COPD diagnosis in the UK primary care setting. PLoS One. 2014;9(9):e105296.

44. Price DB, Baker CL, Zou KH, Higgins VS, Bailey JT, Pike JS. Real-world characterization and differentiation of the Global Initiative for Chronic Obstructive Lung Disease strategy classification. Int J Chronic Obstr Pulm Dis. 2014;9:551-61.

45. Mannino DM, Yu TC, Zhou H, Higuchi K. Effects of GOLD-adherent prescribing on COPD symptom burden, exacerbations, and health care utilization in a real-world setting. Chronic Obstr Pulm Dis. 2015;2(3):223-35.

46. Huang WC, Wu MF, Chen HC, Hsu JY. Features of COPD patients by comparing CAT with mMRC: a retrospective, cross-sectional study. NPJ Prim Care Respir Med. 2015;25:15063.

47. Kim S, Oh J, Kim YI, et al. Differences in classification of COPD group using COPD assessment test (CAT) or modified Medical Research Council (mMRC) dyspnea scores: a cross-sectional analyses. BMC Pulm Med. 2013;13:35. 